\title{
Granulomatous conjunctivitis in a patient with Crohn's disease
}

\author{
WILliAM P. BLASE, DAVID L. KNOX, AND W. RICHARD GREEN \\ From the Wilmer Ophthalmological Institute, the Johns Hopkins Medical Institutions, Baltimore, \\ Maryland, USA
}

SUMMARY A 13-year-old boy with severe, active granulomatous ileocolitis presented with bilateral conjunctival nodules and infiltrates, iritis, and uniocular corneal infiltrates. Gastrointestinal biopsy revealed deep focal ulcers of the bowel wall with adjacent granulomas. Conjunctival biopsy disclosed non-caseating granulomatous inflammation.

Ocular inflammatory lesions have been observed in association with chronic inflammatory bowel disease and, specifically, with the type characterised as 'regional enteritis' or 'Crohn's disease. ${ }^{\prime-3}$ Ophthalmic manifestations of Crohn's disease include recurrent attacks of conjunctivitis, blepharitis, marginal keratitis and corneal ulceration, scleritis, episcleritis, scleromalacia perforans, myositis, uveitis, neuroretinitis, and exudative retinal detachment. ${ }^{1-9}$ The cause of these complications remains obscure. Evidence of extraintestinal granulomatous inflammation in patients with coincident Crohn's disease has been found in the mesenteric lymph nodes, liver, synovia, and bone..$^{7-11}$ We are unaware of any previous report of conjunctival granulomatous inflammation in association with Crohn's disease.

\section{Case report}

A 13-year-old boy was admitted to the Johns Hopkins Hospital with a one-month history of intermittent constipation, diarrhoea, rectal pain, and a recorded weight loss of 15 pounds $(6 \cdot 8 \mathrm{~kg})$. He had been in good health until the gastrointestinal symptoms developed. He had experienced no ophthalmological problems until he developed bilateral eye irritation and redness concomitant with development of the gastrointestinal symptoms.

On admission he was found to be cachectic and in moderate discomfort with flatulence, rectal pain, and left lower quadrant tenderness. Vision was $20 / 20$ in

Correspondence to W. Richard Green, MD, Eye Pathology Laboratory, Johns Hopkins Hospital, 600 N. Wolfe Street, Baltimore, MD 21205, USA.

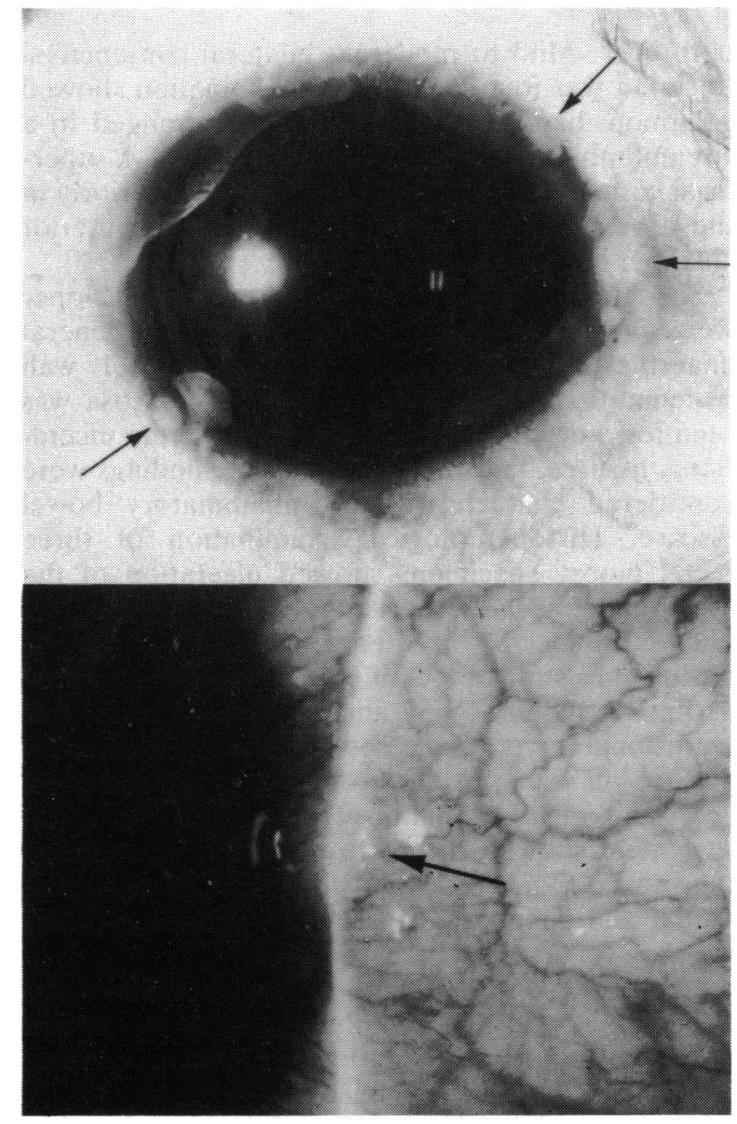

Fig. 1 External (above) and slit-lamp appearance of limbal nodules (arrows) of right eye. 
Fig. 2 Rectal biopsy specimen shows area of ulceration of mucosa (arrow) and intense submucosal inflammatory cell infiltration. (Haematoxylin and eosin, $\times 86$ ).

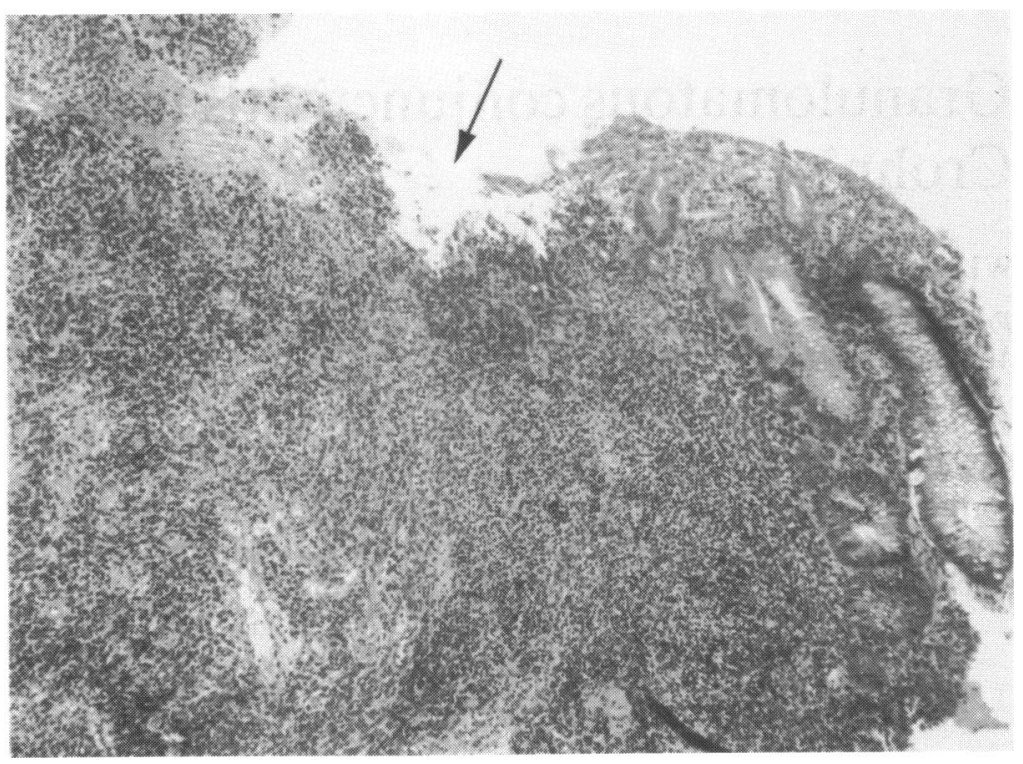

\section{Discussion}

Ocular symptoms in Crohn's disease are well documented, but the mechanisms causing them are not circumlimbal pattern in both eyes (Fig. 1). A superficial corneal stromal infiltrate was seen inferiorly in the left eye. A few cells were present in the anterior chamber of both eyes.

Sigmoidoscopy with biopsy and conjunctival biopsy were performed with the patient under general anaesthesia. On inspection of the bowel wall oedematous hyperaemic friable rectal mucosa was seen for a distance of $8 \mathrm{~cm}$ without discrete ulcerations, fissures, tags, or fistulae. These findings were considered characteristic of inflammatory bowel disease. Histopathological examination of three rectal biopsy specimens showed ulceration of the mucosa (Fig. 2) and marked thickening of the submucosal tissues by an intense inflammatory cell infiltrate consisting of foci of epithelial and giant cells, and some lymphocytes, and plasma cells (Fig. 3). Occasional crypt abscesses with neutrophils and eosinophils were present.

Microscopic examination of the conjunctival biopsy specimens showed chronic round cell infiltration of the substantia propria with discrete nodules of epithelial and giant cells (Fig. 4). Special stains were negative for acid-fast bacilli, bacteria, and fungi. The patient was given $40 \mathrm{mg}$ of oral prednisone during a 2-week period and rapidly recovered from both ophthalmic and gastrointestinal signs and symptoms. Since then he has remained asymptomatic on a maintenance dose of $20 \mathrm{mg}$ of prednisone every other day. 


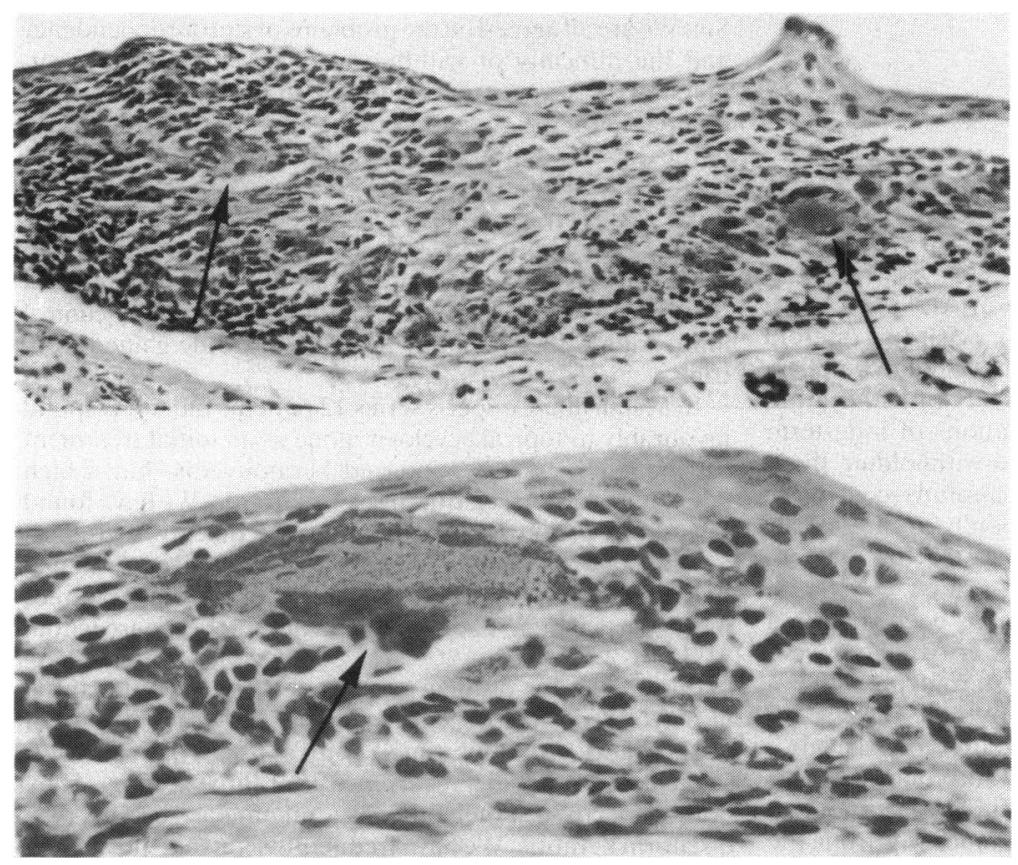

Fig. 4 Two areas of conjunctiva show a round cell infiltrate with epithelial and giant cells (arrows) in substantia propria. (Periodic acidSchiff; upper, $\times 230$; lower, $\times 525)$.

clearly understood. The keratopathy and uveitis seen with Crohn's disease have been thought possibly to represent a type of autoimmune or hypersensitivity reaction to the granulomatous ileocolitis. ${ }^{4 \times}$

The details reported here provide the first histopathological evidence that granulomatous inflammation can occur in the ocular tissues of a patient with Crohn's disease. The simultaneous occurrence and response to treatment provide evidence that the two disorders were related. This case report adds conjunctiva to the list of those tissues which can develop granuloma as an extraintestinal manifestation of Crohn's disease.

\section{References}

1 Crohn BB. Ocular lesions complicating ulcerative colitis. Am J Med Sci 1925; 169: 260)-7.

2 Greenstein AJ, Janowitz HD, Sachar DB. The extraintestinal complications of Crohn's disease and ulcerative colitis: A study of 7(0) patients. Medicine (Baltimore) 1976; 55: 401-12.
3 Hopkins DJ, Horan E, Burton IL, et al. Ocular disorders in a series of 332 patients with Crohn's disease. Br J Ophthalmol 1974; 58: 732-7.

4 Macoul KL. Ocular changes in granulomatous ileocolitis. Arch Ophthalmol 1970; 84: 95-7.

5 Evans PJ, Eustace P. Scleromalacia perforans associated with Crohn's disease. BrJ Ophthalmol 1973; 57: 330-5

6 Reynolds MD, Rankin TJ. Diagnosis of 'rheumatoid variants': Ankylosing spondylitis, the arthritides of gastrointestinal diseases and psoriasis, and Reiter's syndrome. West J Med 1974; 120: 441-7.

7 Knox DL, Bayless TM. Gastrointestinal and ocular discasc. In: Mausolf FA, ed. The eye and systemic disease. 2 nd ed. St Louis: Mosby, 1980: 333-48.

8 Knox DL, Snip RC, Stark WJ. The keratopathy of Crohn's discase. Am J Ophthalmol 1980; 90: 862-5.

9 Schulman MF, Sugar A. Peripheral corneal infiltrates in in flammatory bowel disease. Ann Ophthalmol 1981; 13: 109-10.

10 Nugent FW, Glaser D, Fernandez-Herlihy L. Crohn's colitis associated with granulomatous bone discasc. $N$ EnglJ Med 1976; 294: $262-3$

11 Frayhs R, Stevens MB, Bayless TM. Destructive arthritis and granulomatous synovitis as presenting manifestation of Crohn's disease. Johns Hopkins Med J 1975; 137: 151-5. 